Pesq. Vet. Bras. 28(3):155-160, março 2008

\title{
Febre catarral maligna em bovinos no Estado de Mato Grosso ${ }^{1}$
}

\author{
Fábio S. Mendonça ${ }^{2}$, Renata G.S. Dória ${ }^{3}$, Fábio B. Schein ${ }^{3}$, Sílvio H. Freitas ${ }^{3}$, \\ Luciano Nakazato ${ }^{4}$, Fabiana M. Boabaid ${ }^{4}$, Daphine A.J. Paula ${ }^{4}$, Valéria Dutra ${ }^{4}$ \\ e Edson M. Colodel $4^{*}$
}

\begin{abstract}
Mendonça F.S., Dória R.G.S., Schein F.B., Freitas S.H., Nakazato L., Boabaid F.M., Paula D.A.J., Dutra V. \& Colodel E.M. 2008. [Malignant catarrhal fever in cattle, Mato Grosso, Brazil.] Febre catarral maligna em bovinos no Estado de Mato Grosso. Pesquisa Veterinária Brasileira 28(3):155-160. Departamento de Clínica Médica Veterinária, Faculdade de Agronomia e Medicina Veterinária, Universidade Federal de Mato Grosso, Av. Fernando Corrêa da Costa s/n, Bairro Coxipó, Cuiabá, MT 78068-900, Brazil. E-mail: moleta@ufmt.br

Four outbreaks of malignant catarrhal fever (MCF) in cattle, which had contact with sheep, in Mato Grosso, Brazil, are described. In all cases, the animals had a clinical course of 4 to 7 days with no recovery. Two outbreaks occurred in the municipality of Cuiabá, the first in January 2006 with 8 cattle affected from a herd of 148, and the second in one out of 30 cattle in September 2006. The third outbreak occurred in April 2007 in the municipality of Rondonópolis, where 3 cattle died in a herd of 160 . The fourth outbreak was in the municipality of Caceres in September 2007, where 2 out of 450 cattle were affected. The clinical signs were hyperthermia, intense lacrimation, nasal and oral discharge, corneal opacity, sialorrhea, oral, nasal and genital mucosal erosions, incoordination, depression and death. Necropsy findings in 4 animals were similar and consisted of lymph node swelling, and nasal, oral and esophagus erosion and ulceration. Histologically, arteritis and fibrinoid degeneration was observed in small arteries and arterioles, associated with epithelial necrosis in various organs and tissues. A nested polymerase chain reaction (nPCR) detected ovine herpes virus type 2 in frozen and paraffin embedded tissues in 3 cases.
\end{abstract}

INDEX TERMS: Bovine, malignant catarrhal fever, herpesvirus, vasculitis.

RESUMO.- Relatam-se a ocorrência em quatro propriedades rurais no Estado de Mato Grosso, de casos de febre catarral maligna (FCM) em bovinos criados em contato com ovinos. Todos os casos acompanhados tiveram evolução aguda e não se notou a recuperação dos bovi-

\footnotetext{
${ }^{1}$ Recebido em 30 de outubro de 2007.

Aceito para publicação em 5 de dezembro de 2007.

${ }^{2}$ Doutorando do Programa de Pós-Graduação em Ciência Veterinária, Departamento de Morfologia e Fisiologia Animal da Universidade Federal Rural de Pernambuco, Rua Dom Manoel de Medeiros s/n, Dois Irmãos, Recife, PE 52171-900, Brasil.

${ }^{3}$ Faculdade de Medicina Veterinária da Universidade de Cuiabá, Rua Itália s/n, Jardim Europa, Cuiabá, MT 78065-480, Brasil.

${ }^{4}$ Departamento de Cínica Médica Veterinária, Universidade Federal de Mato Grosso, Av. Fernando Corrêa s/n, Coxipó, Cuiabá, MT 78060900, Brasil. *Autor para correspondência: moleta@ufmt.br
}

nos. Dois casos ocorreram no município de Cuiabá. No primeiro, em janeiro de 2006, adoeceram e morreram 8 animais de um rebanho com 148 bovinos, no outro, morreu 1 de um rebanho com 30 animais em setembro de 2006. Um terceiro caso foi notado no município de Rondonópolis, onde morreram 3 de 160 bovinos em abril de 2007. O último caso relatado ocorreu no município de Cáceres no mês de setembro de 2007, morrendo 2 de 450 bovinos. O curso clínico variou de 4 a 7 dias. Os principais sinais clínicos foram hipertermia, lacrimejamento intenso, corrimento catarral nasal e oral, opacidade de córnea, sialorréia, diarréia, erosão da mucosa oral, nasal e genital, incoordenação motora, depressão e morte. Aumento do volume de linfonodos, erosões e úlceras na cavidade oral, nasal e esôfago foram achados constantes em quatro bovinos necropsiados. Arterite com degenera- 
ção fibrinóide em arteríolas e pequenas artérias, a necrose do epitélio de revestimento em vários órgãos e tecidos foram os principais achados histológicos. Através da técnica de reação em cadeia da polimerase "nested" (nPCR), o DNA do Herpesvírus Ovino tipo 2 foi detectado em tecido parafinado ou congelado em 3 de 4 bovinos deste estudo.

TERMOS DE INDEXAÇÃO: Bovinos, febre catarral maligna, herpesvírus, vasculite.

\section{INTRODUÇÃO}

A febre catarral maligna (FCM) é uma doença infecciosa viral, pansistêmica, frequentemente fatal e com ampla distribuição geográfica (Plowright 1990, Loken et al. 1998, Driemeier et al. 2002). A FCM afeta principalmente ruminantes domésticos e selvagens (Li et al. 2003) e é caracterizada por distúrbios cutâneos, digestivos, respiratórios e neurológicos.

A doença é causada por um vírus do gênero Rhadinovirus, pertencente à família Gammaherpesvirinae (Coulter et al. 2001). Até o momento foram identificados quatro tipos de vírus que causam FCM em animais ( $\mathrm{Li}$ et al. 2003), sendo a forma africana, produzida pela cepa Alcelaphine Herpesvírus 1 (AlHV-1), a forma ovino-associada (FCM-OA), produzida pelo herpesvírus ovino-2 (OvHV-2), um terceiro vírus que induz a FCM clássica no veado-de-cauda-branca (Odocoileus virginianus) (Li et al. 2000), além de um vírus endêmico em cabras domésticas atualmente denominado herpesvírus caprino-2 ou CpHV-2 (Chmielewicz et al. 2001, Li et al. 2001). No Brasil, a FCM é frequentemente relacionada ao herpesvírus ovino do tipo 2 (OvHV-2) (Garmatz et al. 2004).

Macroscopicamente ocorrem, na FCM, erosões, úlceras, hiperemia e congestão, principalmente no trato digestivo, respiratório superior e urinário, linfonodos, fígado, rim, olhos e encéfalo, além de exantema cutâneo (Barker et al. 1993, Rech et al. 2005). Histologicamente, as lesões consistem de vasculite com necrose fibrinóide, infiltrados mononucleares em vários órgãos, hiperplasia linfóide e necrose dos epitélios de revestimento são características para a doença (Barker et al. 1993, Barnard et al. 1994, Rech et al. 2005).

A técnica da PCR é preconizada para a confirmação do diagnóstico em casos de FCM-OA (Baxter et al. 1993, O'Toole et al.1995, Simon et al. 2003, Garmatz et al. 2004). A técnica é sensível e específica (Müller-Doblies et al. 1998) e pode ser realizada em tecidos frescos e fixados em formol (Crawford et al. 1999). As limitações desta técnica quando aplicada a materiais fixados em formol estão relacionadas à desnaturação do ácido nucléico por fixação muito prolongada ou em formol não-tamponado (Crawford et al. 1999, Garmatz et al. 2004).

A doença foi documentada em bovinos em várias regiões do Brasil, como Nordeste (Figueiredo et al. 1990, Silva 2001, Riet-Correa et al. 2003, Macedo et al. 2007), Sudeste (Marques et al. 1986, Lemos et al. 2005), Cen-
tro-Oeste (Lemos et al. 2005) e Sul (Garmatz et al. 2004). Visando contribuir para o estudo da FCM em bovinos no Brasil, descrevemos neste trabalho os achados epidemiológicos, clínicos, patológicos e moleculares da doença no Estado de Mato Grosso.

\section{MATERIAL E MÉTODOS}

O histórico clínico foi obtido em entrevistas com veterinários e proprietários nas propriedades problemas. Dois bovinos, um do município de Cuiabá (Caso 1) e o outro do município de Rondonópolis (Caso 2), foram examinados clinicamente e após a morte espontânea, foram necropsiados por veterinários de campo e as amostras coletadas durante a necropsia foram encaminhadas para o Laboratório de Patologia Veterinária da Universidade Federal de Mato Grosso (LPV-UFMT). Um terceiro bovino (Caso 3), fêmea, de 8 meses, raça mista, foi atendido no Setor de Clínica de Grandes Animais do Hospital Veterinário da Faculdade de Medicina Veterinária da Universidade de Cuiabá. Após o exame clínico e a coleta de amostras de sangue para análise clínica, o bovino foi eutanasiado in extremis. $O$ quarto bovino, fêmea, nelore, 8 anos de idade, foi necropsiado durante a visita de técnicos do LPV-UFMT à propriedade no município de Cáceres-MT. Fragmentos de vísceras dos quatro bovinos foram fixados em solução de formol a $10 \%$ e processados rotineiramente para exame histológico. Amostras de tecido nervoso (Caso 1 e 4) e baço (Caso 4) foram armazenadas a $-20^{\circ} \mathrm{C}$ para realização de PCR no Laboratório de Biologia Molecular da UFMT.

Para realização da nPCR amostras de DNA foram extraídas de tecido nervoso fresco e baço (Casos 1 e 4) e de tecidos emblocados em parafina (Casos 2 e 3). O tecido parafinado foi seccionado em pequenos fragmentos (cerca de $25 \mathrm{mg}$ ) sendo a extração de DNA de acordo (Garmatz et al. 2004). As amostras de tecidos congelados foram submetidas ao método padrão de extração proteinase $\mathrm{K} /$ fenol/clorofórmio e precipitação com etanol (Sambrook \& Russel 2001).

As condições da nPCR foi adaptada segundo (Baxter et al. 1993), utilizando os pares de primers 556 (AGTCTGGGTATATGAATCCAGATGGCTCTC) e 755 (AAGATAAGCACCAGTTATGCATCTGATAAA) para primeira reação e para PCR secundária utilizou-se $1 \mu \mathrm{l}$ do produto da PCR primária ao invés do DNA extraído; com primers 556 e 555 (5'TTCTGGGGTAGTGGCGAGCGAAGGCTTC-3'). Um total de $8 \mu 1$ de cada produto da PCR foi avaliado em gel de agarose $2 \%$ contendo brometo de etídeo e analisados em transiluminador.

\section{Dados epidemiológicos}

\section{RESULTADOS}

Dados epidemiológicos sobre os casos de FCM em bovinos no Estado de Mato Grosso estão dispostos no Quadro 1. As quatro propriedades onde ocorreram casos de FCM eram pequenas, com até 500 ha e tinham criações mistas de ovinos e bovinos. No Caso 1, o surto de mortes de bovinos ocorreu entre os meses de janeiro e fevereiro de 2006, morreram $8(5,4 \%)$ de um lote de 148 bovinos, com idade entre 8 meses e 4 anos. Todos os bovinos que manifestaram sinais clínicos morreram. Os bovinos eram criados no local anterior à aquisição da propriedade há pelo menos 20 anos, e os ovinos foram adquiridos no ano de 2004. A mortalidade coincidiu com o 


\begin{tabular}{cccccc}
\multicolumn{3}{c}{$\begin{array}{c}\text { Quadro 1. Aspectos epidemiológicos de febre catarral } \\
\text { maligna em bovinos no Estado de Mato Grosso }\end{array}$} \\
\hline Caso & $\begin{array}{c}\text { Contato } \\
\text { ovinos }\end{array}$ & $\begin{array}{c}\text { Mês/ano da } \\
\text { ocorrência }\end{array}$ & \multicolumn{3}{c}{ Número de bovinos } \\
\cline { 4 - 6 } & Sim & Jan/2006 & 148 & 8 & 8 \\
1 & Sebanho & Doentes & Mortos \\
\hline 2 & Sim & Set/2006 & 30 & 1 & 1 \\
3 & Sim & Abr/2007 & 160 & 3 & 3 \\
4 & Sim & Set/2007 & 450 & 2 & 2
\end{tabular}

período de parição dos ovinos. Não ocorreram alterações significativas de manejo na propriedade e após dezoito meses da última morte associada à FCM não se observaram outros casos similares. No Caso 2, ocorrido no município de Rondonópolis-MT, morreram 3 (1,9\%) de 160 bovinos Nelore, fêmeas, 2-3 anos de idade, durante o mês de setembro de 2006. Os ovinos, rebanho com 40 animais, que estavam em época de parição, eram criados consorciados ao rebanho de bovinos. Todos os bovinos com sinais clínicos morreram.

No Caso 3, ocorrido numa propriedade situada na grande Cuiabá, eram criados 30 bovinos com aptidão para a produção de leite. Destes animais, uma bezerra de 8 meses de idade adoeceu e morreu após curso clínico de 10 dias. A manifestação dos sinais clínicos se deu cerca de 5 semanas após a introdução de 11 ovinos na propriedade e coincidiu com a parição de algumas ovelhas. Os ovinos foram retirados da propriedade e após 12 meses de acompanhamento clínico na propriedade não se notaram outros casos de FCM em bovinos do rebanho.

O Caso 4 foi observado no município de Cáceres, fazenda em área de Fronteira com a Bolívia. Na propriedade com 500 hectares, há aproximadamente 15 anos criava-se por volta de 400 bovinos e 300 ovinos. Os sinais clínicos de FCM foram observados no mês de setembro de 2007, com morte de dois bovinos. Não foi relatada a introdução recente de ovinos na propriedade. Não havia controle reprodutivo de ovinos, ocorrendo parição ao longo do ano.

\section{Sinais clínicos}

A evolução clínica da doença nos bovinos variou de 4 a 10 dias. Os principais achados clínicos foram hipertermia, apatia, anorexia, dispnéia, corrimento ocular, corrimento nasal e oral inicialmente seroso e posteriormente catarral (Fig.1), salivação, emagrecimento e morte. Nos 4 bovinos necropsiados havia opacidade bilateral de córnea, conjuntivite, aumento de volume dos linfonodos submandibulares e pré-escapulares. No Caso 3 havia sons anormais à auscultação da traquéia, inflamação e necrose da vulva e espaços interdigitais. O corrimento nasal, inicialmente seroso, evoluiu rapidamente para muco-purulento espesso. Constataram-se também tremores musculares, nistagmo e desprendimento da capa córnea dos cascos (Fig.2). O hemograma deste bovino revelou leucocitose por neutrofilia (leucócitos totais 25.100/ $\mathrm{mm}^{3}$; neutrófilos segmentados $13.554 / \mathrm{mm}^{3}$ ), linfocitose absoluta $\left(11.044 / \mathrm{mm}^{3}\right)$, hiperfibrinogenemia $(800 \mathrm{mg} / \mathrm{dL})$ e hipoproteinemia.

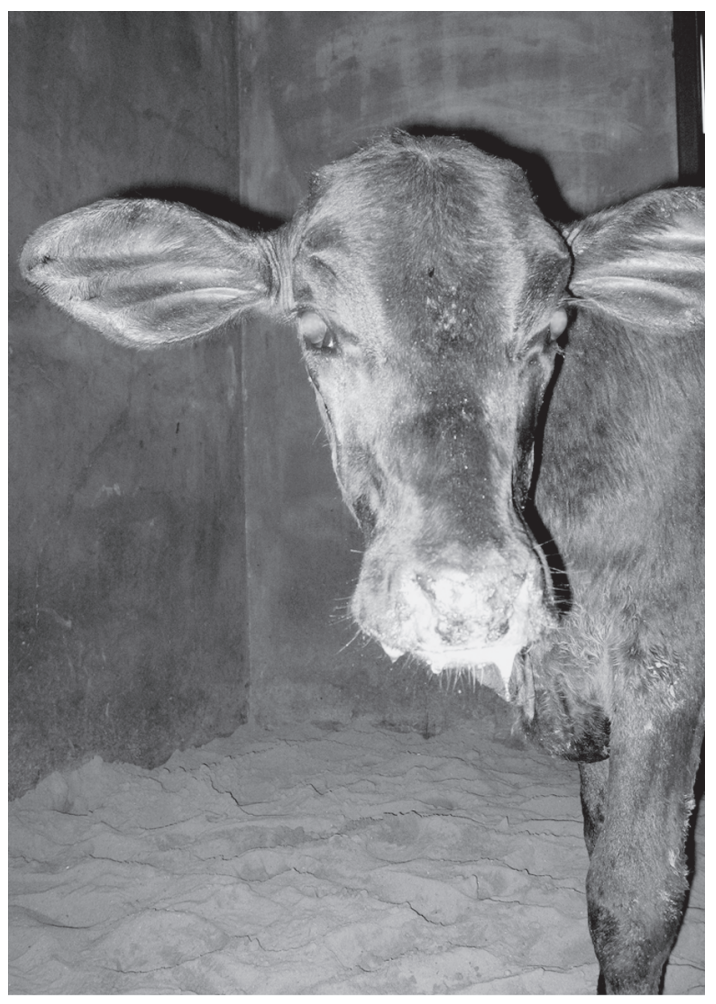

Fig.1. Febre catarral maligna em bovinos no Estado de Mato Grosso. Úlcera de focinhos, opacidade de córnea e corrimento nasal e oral catarral.

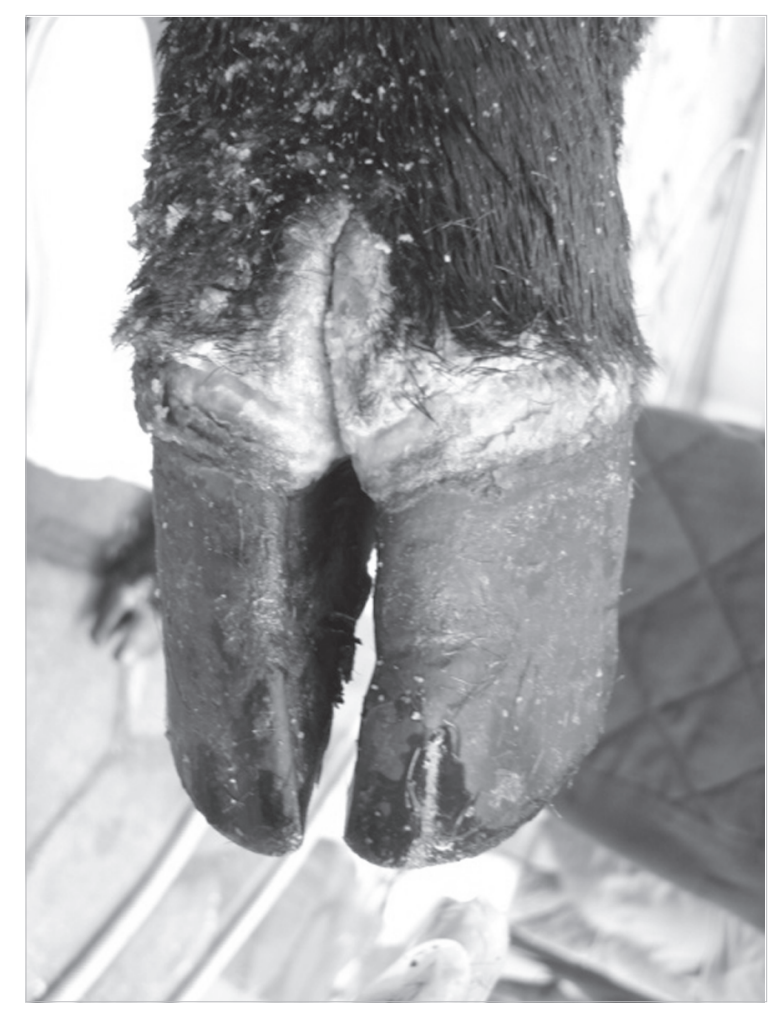

Fig.2. Membro anterior de bovino com febre catarral maligna. Desprendimento da capa córnea do casco. 


\section{Achados de necropsia}

$\mathrm{Na}$ necropsia os principais achados foram erosões e úlceras na cavidade oral e nasal, esôfago e bexiga urinária. Necrose de papilas orais foi observada nos Casos 3 e 4. No Caso 3 havia evidente descolamento de estojo córneo do casco dos membros anteriores e erosões e úlceras nos pré-estômagos, abomaso e alças intestinais que tinham acúmulo de secreção fibrinopurulenta. No trato respiratório notou-se avermelhamento difuso com deposição superficial de exsudado fibrinoso e por vezes purulento principalmente na traquéia. Notou-se também aumento de volume de linfonodos, principalmente no trato digestivo, que estavam com edema e hemorragia ao corte. Evidenciação dos vasos da leptomeninge foi achado constante. Nos Casos 1 e 4 havia o aumento discreto de linfonodos, úlceras no espelho nasal, que estava revestido por crosta de fibrina. O fígado tinha aumento do padrão lobular e a adrenal estava levemente tumefeita e tinha hemorragia de cortical, nos rins havia múltiplos focos brancacentos principalmente na superfície subcapsular.

\section{Achados histopatológicos}

Com variável intensidade e distribuição, inflamação perivascular e degeneração fibrinóide da parede dos vasos arteriolares e arteriais e necrose epitelial associado com infiltrado inflamatório foram achados constantes nos diferentes casos estudados. As alterações vasculares que ocorreram em diferentes órgãos foram caracterizadas por infiltrado mononuclear na região perivascular com hialinização e infiltrado de linfócitos, plasmócitos e histiócitos na túnica média e adventícia. Havia na luz de alguns vasos trombos constituídos predominantemente por fibrina. Estes achados foram constantemente observados no encéfalo (Fig.3), plexos coróides ventriculares (Fig.4), fígado, linfonodos, baço, bexiga, frequentemente encontrados no rim (3 casos), adrenal (3 casos), coração ( 2 casos) e pulmão (2 casos). O epitélio de revestimento do trato digestivo e respiratório tinha áreas multifocais extensas com necrose coagulativa associada a infiltrado e vasculite mononuclear (Fig.5). Nos linfonodos e baço foi notada depleção linfóide e vasculite mononuclear com necrose fibrinóide de parede dos vasos. No encéfalo, a vasculite meningeana era discreta a leve e havia irregular intensidade de infiltrado mononuclear e necrose fibrinóide, principalmente em vasos da substância branca.

Na análise de "nested PCR", todos apresentaram amplificação no tecido nervoso com exceção do Caso 3, para herpesvírus ovino tipo 2. No caso 4 , além de amostras de tecido nervoso, o baço também apresentou amplificação para o OHV-2 (Fig.6).
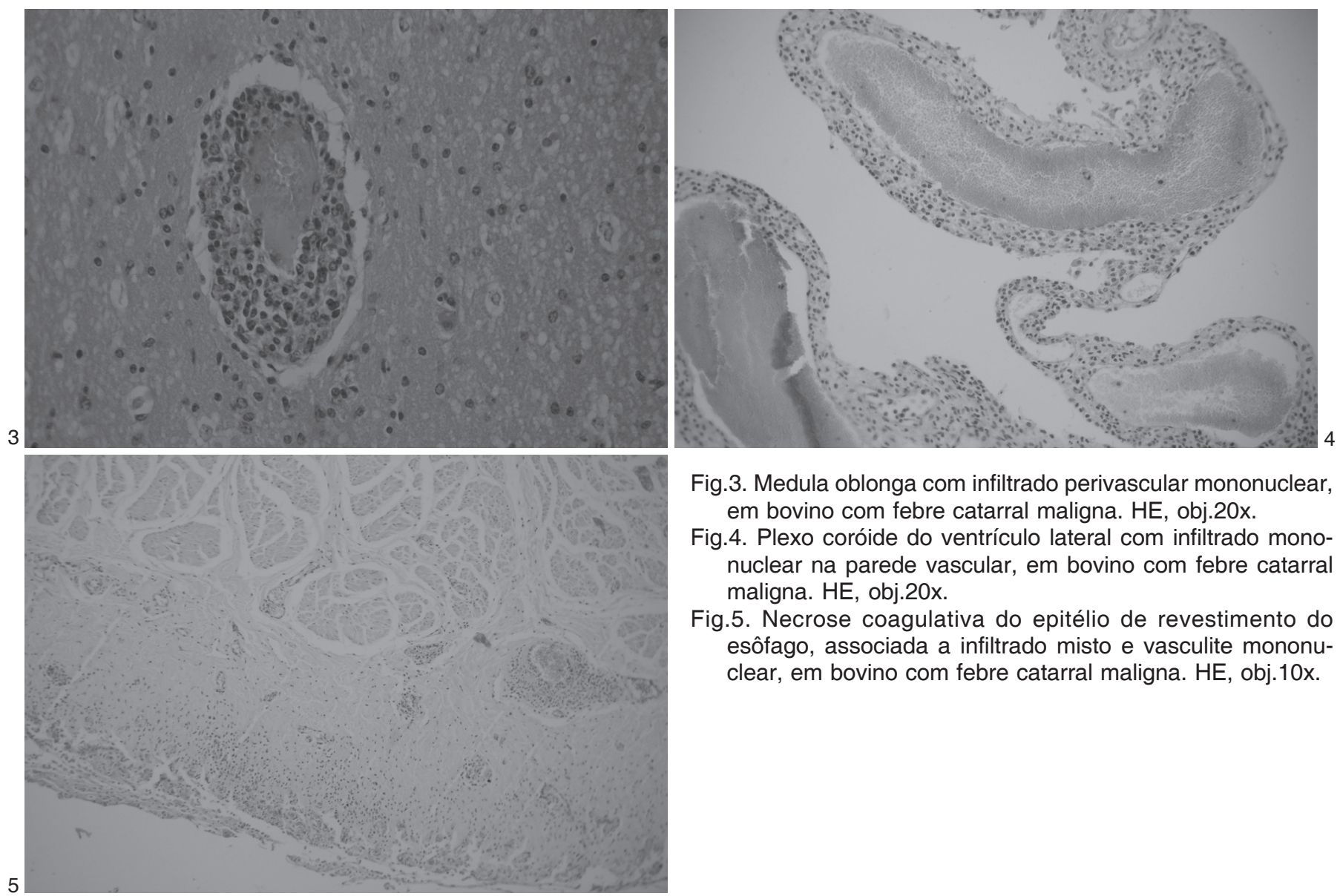

Fig.3. Medula oblonga com infiltrado perivascular mononuclear, em bovino com febre catarral maligna. HE, obj.20x.

Fig.4. Plexo coróide do ventrículo lateral com infiltrado mononuclear na parede vascular, em bovino com febre catarral maligna. HE, obj.20x.

Fig.5. Necrose coagulativa do epitélio de revestimento do esôfago, associada a infiltrado misto e vasculite mononuclear, em bovino com febre catarral maligna. HE, obj.10x. 


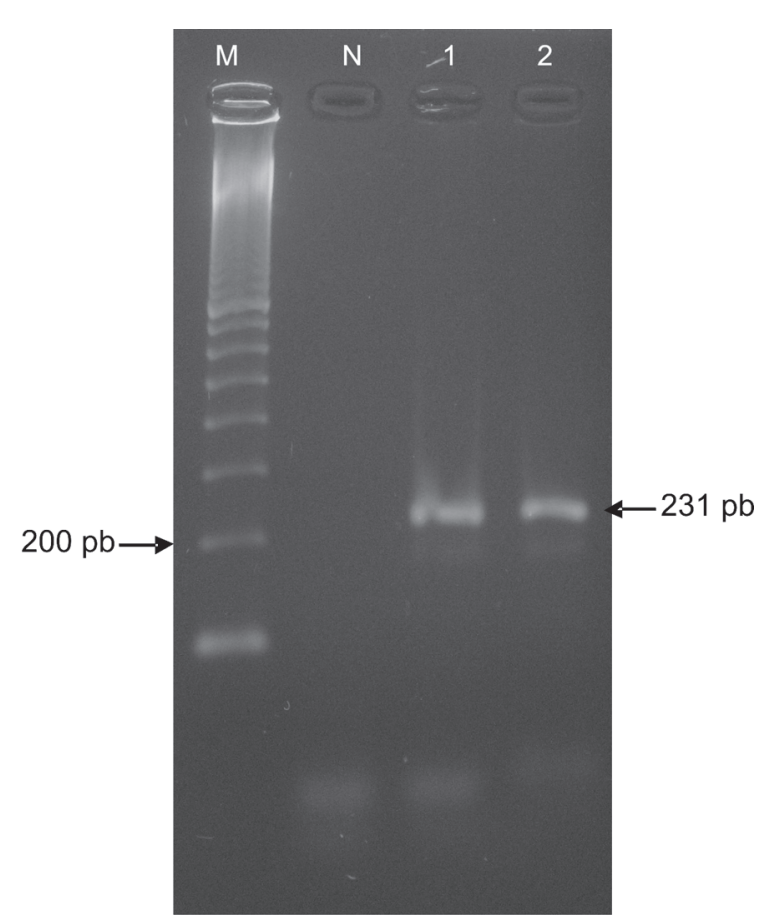

Fig.6. "Nested PCR" de amostras clínicas de febre catarral maligna em bovino no Estado de Mato Grosso (Caso 4). M: marcador de massa molecular (100 base-pair Ladder); N: controle negativo; 1 : nPCR de DNA de baço e 2: nPCR de DNA de gânglio trigêmeo.

\section{DISCUSSÃO E CONCLUSÕES}

A confirmação diagnóstica nos casos aqui relatados foi baseada nos dados epidemiológicos, sinais clínicos, lesões características da enfermidade e detecção molecular de DNA viral, similares aos descritos em outros casos de febre catarral maligna no Brasil (Döbereiner \& Tokarnia 1959, Barros et al. 1983, Figueiredo et al. 1990, Baptista \& Guidi 1998, Lemos et al. 2005, Rech et al. 2005, Macêdo et al. 2007).

Em bovinos, os sinais clínicos e achados de necropsia como os que são relatados neste trabalho, são importantes para o diagnóstico presuntivo de FCM. A conclusão diagnóstica foi estabelecida através das lesões histológicas (Plowright 1990) e da amplificação de fragmentos de DNA do OvHV-2 em amostras de tecidos dos bovinos com lesões de FCM. Somente o Caso 3 não apresentou amplificação na nPCR provavelmente devido a prolongado período do tecido em formol (Garmatz et al. 2004).

No Estado de Mato Grosso, FCM já foi clínica e patologicamente diagnosticados em veados (Mazama goauzoubira) e confirmados através de ensaios de PCR de animais doentes. Nessa ocasião, se relatou um surto em que sete veados adoeceram no Zoológico da UFMT, Cuiabá (Driemeier et al. 2002). Em outras regiões do país como no Rio Grande do Sul, o diagnóstico de FCM foi confirmado pela reprodução experimental da doença e pela determinação genômica de OvHV-2 nos tecidos de bovinos afetados (Garmatz et al. 2004), sugerindo que o vírus que circula e produz a doença no Brasil é OvHV-2.

Em um dos surtos acompanhado, a forma epizoótica da doença foi observada, morrendo vários animais de um mesmo rebanho. Posteriormente a este surto, mesmo não havendo alterações de manejo, permanecendo o contato entre bovinos e ovinos, durante 18 meses de observação, a doença não foi mais notada na propriedade. As demais ocorrências de FCM em bovinos no Estado foram consideradas esporádicas com no máximo 3 casos por rebanho.

Devido à similaridade com outras doenças a vírus, tais como febre aftosa, estomatite vesicular e diarréia viral bovina-doença das mucosas (BVD-MD), o diagnóstico de FCM em bovinos deve ser baseado nos critérios epidemiológicos, clínicos e patológicos (Barker et al. 1993). A lesão histológica pode ajudar no diagnóstico de FCM, mas mesmo assim, as semelhanças entre FCM e BVD-MD existem, pois necrose hialina e fibrinóide das artérias mesentéricas e da submucosa do intestino são observadas em ambas as doenças. Entretanto, sabe-se que vasculite da rete mirabile carotídea é um achado importante para caracterização da FCM em bovinos. (Riet-Correa et al. 2003, Lemos et al. 2005, Rech et al. 2005), podendo ser considerado um achado constitutivo da FCM (Barker et al. 1993).

Acredita-se que a transmissão da FCM-OA esteja relacionado ao contato de ovinos, principalmente em época de parição, com bovinos. Nesse trabalho, os diagnósticos de FCM no Estado de Mato Grosso, coincidem com a expansão da pecuária ovina que passou de 40000 cabeças após o ano de 2000 para aproximadamente 700000 cabeças atualmente. A sazonalidade observada em Estados do Nordeste (Macedo et al. 2007) e do Sul (Rech et al. 2005) não foi estabelecida nesse estudo. Acredita-se que a influência de fotoperíodo com mais de um período de parição para ovinos na região Centro-Oeste por ano, além do curto período de observação, estejam relacionados com essa inconsistência.

\section{REFERÊNCIAS}

Baptista F.Q. \& Guide P.C. 1998. FCM no Estado do Paraná. Hora Vet., Porto Alegre, 45:33-37.

Barker I. K., Van Dreumel A.A. \& Palmer N. 1993. The alimentary system, p.1-30. In: Jubb K.V.C., Kennedy P.C. \& Palmer N. (ed.), Pathology of Domestic Animals. Vol.2. 4th ed. Academic Press, San Diego.

Barnard B.J.H., Van der Lugt J.J. \& Mushi E.Z. 1994. Malignant catarrhal fever, p.946-957. In: Coetzer J.A.W., Thomson G.R. \& Tustin R.C. (ed.), Infectious Diseases of Livestock with Special Reference to Southern Africa. Vol.2. Oxford University Press, Cape Town.

Barros S.S., Santos M.N. \& Barros C.S.L. 1983. Surto de febre catarral maligna em bovinos no Rio Grande do Sul. Pesq. Vet. Bras. 3:81-86.

Baxter S.I., Pow I., Bridgen A. \& Reid H.W. 1993. PCR detection of the sheep-associated agent of malignant catarrhal fever. Arch. Virol. 132:145-159.

Chmielewicz B., Goltz M. \& Ehlers B. 2001. Detection and multigenic characterization of a novel gammaherpesvirus in goats. Virus Res. 75:87-94.

Coulter L.J., Wright H. \& Reid H.W. 2001. Molecular genomic characterization of the viruses of malignant catarrhal fever. J. Comp. Pathol. 124:2-19. 
Crawford T.B., Li H., O'Toole D.1999. 1999. Diagnosis of malignant catarrhal fever by PCR using formalin-fixed, paraffin-embedded tissues. J. Vet. Diagn. Invest. 11:111-116.

Döbereiner J. \& Tokarnia C.H. 1959. Ocorrência da coriza gangrenosa dos bovinos no município de Serra Negra do Norte, Rio Grande do Norte. Arqs Inst. Biol. Animal, Rio de J., 2:65-82

Driemeier D., Brito M.F., Traverso S.D., Cattani C. \& Cruz C.E.F. 2002. Outbreak of malignant catarrhal fever in brown brocket deer (Mazama gouazoubira) in Brazil. Vet. Rec. 151:271-272.

Figueiredo L.J.C., Castelo Branco M.B. \& Oliveira A.C. 1990. Aspectos clínicos e epidemiológicos da FCM. Anais 16 Congresso Mundial de Buiatria, Salvador, p.666-671.

Garmatz S.L., Irigoyen L.F., Rech R.R., Brown C.C., Zhang J. \& Barros C.S.L. 2004. Febre catarral maligna em bovinos no Rio Grande do Sul: transmissão experimental para bovinos e caracterização do agente etiológico. Pesq. Vet. Bras. 24:93-106.

Lemos R.A.A., Rech R.R., Guimarães E.B., Kadri A. \& Dutra I.S. 2005. Febre catarral maligna em bovinos do Mato Grosso de Sul e de São Paulo. Ciência Rural, Santa Maria, 35:932-934.

Li H., Dyer N., Keller J. \& Crawford T.B. 2000. Newly recognized herpesvirus causing malignant catarrhal fever in white-tailed deer (Odocoileus virginianus). J. Clin. Microbiol. 38:1313-1318.

Li H., Keller J., Knowles D.P. \& Crawford T.B. 2001. Recognition of another member of the malignant catarrhal fever virus group: an endemic gammaherpesvirus in domestic goats. J. Gen. Virol. 82:227-232

Li H., Gailbreath K., Bender L.C., West K., Keller J. \& Crawford T.B. 2003. Evidence of three new members of malignant catarrhal fever virus group in muskox (Ovibos moschautus), Nubian ibex (Capra nubiana) and gemsbock (Oryx gazella). J. Wld. Dis. 39:875-880.

Loken T., Aleksandersen M., Reid H. \& Pow I. 1998. Malignant catarrhal fever caused by ovine herpesvirus-2 in pigs in Norway. Vet. Rec. 143:464-467.

Macêdo J.T.S.A., Riet-Correa F., Simões S.V.D., Dantas A.F.M. \& No- bre V.M.T. 2007. Febre catarral maligna em bovinos na Paraíba. Pesq. Vet. Bras. 27:277-281.

Marques L.C, Alessi A.C., Bechara G.H., Tomaz B.V., Marques J.A \& Guerra L. 1986. Surto de febre catarral maligna em bovinos no estado de São Paulo. Arq. Bras. Med. Vet. Zootec. 38:719-729.

Muller-Doblies U.U., Li H., Hauser B., Adler H. \& Ackermann M. 1998. Field validation of laboratory tests for clinical diagnosis of sheepassociated malignant catarrhal fever. J. Clin. Microbiol. 36:2970-2972.

O'Toole D., Li H., Roberts S., Rovnak J., DeMartini J.C., Cavender J., Williams B. \& Crawford T.B. 1995. Chronic generalized obliterative arteriopathy in cattle: a sequel to sheep-associated malignant catarrhal fever. J. Vet. Diagn. Invest. 7:108-121.

Plowright W. 1990. Malignant catarrhal fever virus, p.123-150. In: Morein B. \& Dinter Z. (ed.), Virus Infections of Ruminants. Elsevier Science Publishers, Amsterdam.

Rech R.R., Schild A.L., Driemeier D., Gamatz S.L., Oliveira F.N., RietCorrea F. \& Barros C.S.L. 2005. Febre catarral maligna em bovinos no Rio Grande do Sul: epidemiologia, sinais clínicos e patologia. Pesq. Vet. Bras. 25:97-105.

Riet-Correa F., Tabosa I.M., Azevedo E.O., Medeiros R.M.T., Simões S.V.D., Dantas A.F.M., Alves C.J., Nobre V.M.T., Athayde A.C.R., Gomes A.A. \& Lima E.F. 2003. Doenças dos Ruminantes e Eqüinos no Semi-Árido da Paraíba. Febre catarral maligna. Semi-Árido em Foco. 1:12-13.

Sambrook J. \& Russel D.W. 2001. Molecular Cloning: a Laboratory Manual. Cold Spring Harbor Laboratory.

Silva S.M.M.S., Cavalcante H.S., Viana G.E.N., Barbosa A.A. \& Silva S.A.V. 2001. Surto de febre catarral maligna. Anais 9o Enapave, Pirassununga, p.70.

Simon S., Li H., O'Toole D., Crawford T.B. \& Oaks JL. 2003. The vascular lesions of a cow and bison with sheep-associated malignant catarrhal fever contain ovine herpesvirus 2-infected CD8(+) T lymphocytes. J. Gen. Virol. 84:2009-2013. 